\title{
Does the critical shoulder angle decrease after acromioplasty? A systematic review and meta-analysis
}

\author{
Mingtao Zhang (1), Zhitao Yang, Borong Zhang, Tao Liu, Jin Jiang ${ }^{*}$ and Xiangdong Yun * (1)
}

\begin{abstract}
Background: Rotator cuff tears are one of the most common shoulder injuries in the older population. This study aimed to determine whether acromioplasty reliably decreases the critical shoulder angle (CSA) and describe any associated complications.

Methods: A systematic literature review was performed according to PRISMA guidelines using PubMed, EMBASE, Web of Science, and Cochrane Library Database. Two reviewers independently screened the titles and abstracts using prespecified criteria. Studies where the acromioplasty was performed as a surgical procedure were included. Patient characteristics and degree of CSA reduction were collected from each individual study. All statistical analyses were performed using Review Manager (RevMan) 5.4.1 software. A random-effects model was used for meta-analysis.

Results: A total of 9 studies involving 1236 patients were included in the meta-analysis. The age of patients ranged from 23 to 82 years. The follow-up period ranged from 12 to 30 months. Of the 9 studies, 8 (88.9\%) were retrospective, $1(11.1 \%)$ was prospective, 5 were comparative, and 4 were case series. The mean CSA was significantly reduced from $36.1^{\circ} \pm 4.6^{\circ}$ to $33.7^{\circ} \pm 4.2(p<0.05)$. The meta-analysis showed an overall best estimate of the mean difference in preand postoperative CSA equal to $2.63^{\circ}$ (95\% confidence interval: $\left.2.15,3.11\right](p<0.00001)$.

Conclusions: Acromioplasty can significantly reduce CSA, notably in cases of high preoperative CSA. In addition, the effect of lateral acromioplasty on the CSA was more significant compared to anterolateral acromioplasty. Acromioplasty was not associated with complications during the short-term follow-up.
\end{abstract}

Keywords: Critical shoulder angle, Acromioplasty, Systematic review

\section{Introduction}

Rotator cuff tears (RCTs) are one of the most common shoulder injuries in the general older population $[1,2]$. Among people aged $>60$ years, the incidence of RCTs is estimated at $>10 \%$ [3]. While the pathogenesis of degenerative RCTs is multifaceted, the precise mechanisms are still unclear [4]. RCTs result from numerous risk factors, including intrinsic and extrinsic factors. The extrinsic risk

\footnotetext{
*Correspondence: jiangjin2007@163.com; xiangdongyun@126.com Department of Orthopaedics, Lanzhou University Second Hospital, No. 82 Cuiyingmen, Chengguan District, Lanzhou 730030, Gansu, China
}

factors, especially acromial morphology, have attracted the attention of many scholars. Numerous studies have reported that a higher acromion index, as well as type III and lower lateral acromion angles, are significantly related to degenerative RCTs [5-7].

The correlation between degenerative RCTs and the CSA has recently received increasing attention $[8,9]$. The CSA, first mentioned in RCT research in 2013 by Moor et al. [10], is defined as the angle between the superior and inferior bony margin of the glenoid and the lateral margin of the acromion (Fig. 1). The CSA can be quantified by standard radiographic imaging of the shoulder. Moor et al. [10] reported that patients with CSAs $>35^{\circ}$ original author(s) and the source, provide a link to the Creative Commons licence, and indicate if changes were made. The images or other third party material in this article are included in the article's Creative Commons licence, unless indicated otherwise in a credit line to the material. If material is not included in the article's Creative Commons licence and your intended use is not permitted by statutory regulation or exceeds the permitted use, you will need to obtain permission directly from the copyright holder. To view a copy of this licence, visit http://creativecommons.org/licenses/by/4.0/. The Creative Commons Public Domain Dedication waiver (http://creativeco mmons.org/publicdomain/zero/1.0/) applies to the data made available in this article, unless otherwise stated in a credit line to the data. 


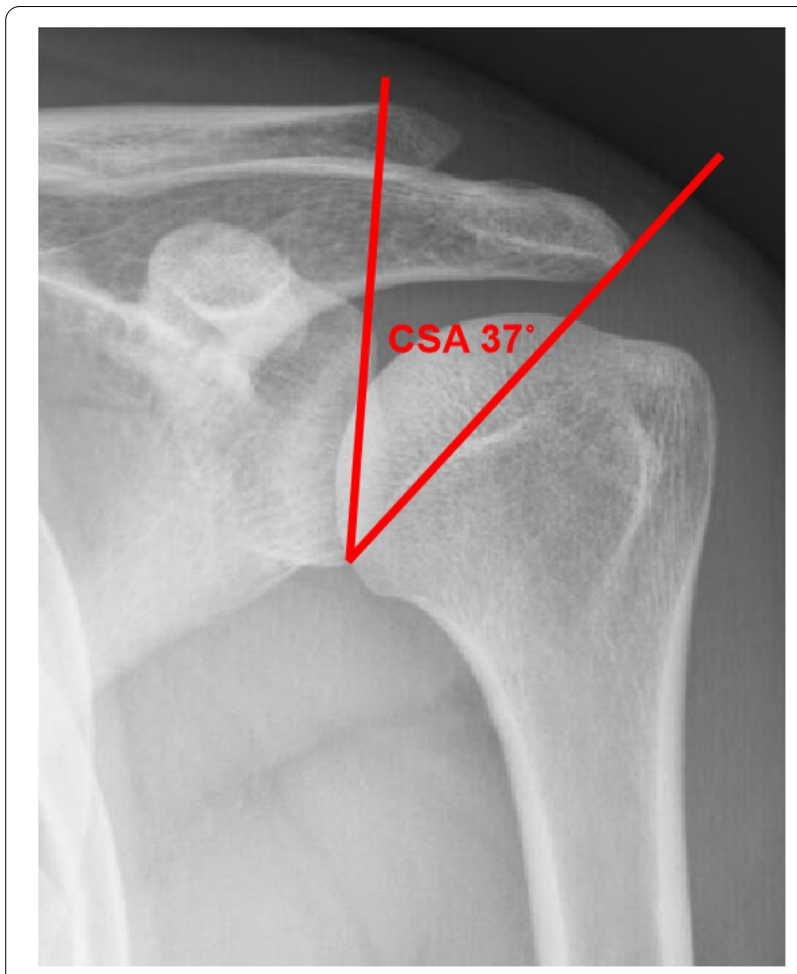

Fig. 1 The critical shoulder angle (CSA) measured on true anteroposterior radiographs

had a higher rotator cuff tear rate compared to those with CSAs $\leq 35^{\circ}$. In addition, a recent study found that CSAs $>38^{\circ}$ postoperatively increased a patient's risk of rotator cuff retear in 14-fold [11]. Gerber et al. [12] found that patients with CSAs $>35^{\circ}$ had a higher retear rate after repair than those with $\mathrm{CSA}<33^{\circ}$ after lateral acromioplasty. However, a recent meta-analysis showed that it was difficult to obtain an exact association between the CSA and degenerative rotator cuff tears [13].

Acromioplasty was originally described in 1972 by Neer et al. [14] to solve the anteroinferior bone impingement of the rotator cuff tendon. Ellman et al. [15] were the first to establish the principles of arthroscopic acromioplasty in 1987. Some studies have demonstrated that anterolateral or lateral acromioplasty can significantly reduce the CSA [12, 16]. Katthagen et al. [17] demonstrated that the CSA can be reduced by arthroscopic anterolateral or lateral acromioplasty in a cadaveric study. In addition, Kaiser et al. [18] reported that lateral acromioplasty reduced the CSA more significantly than anterolateral acromioplasty in an anatomical study. However, Olmos et al. [19] demonstrated that the CSA cannot always be reduced to $<35^{\circ}$ by arthroscopic lateral acromioplasty, especially in patients with preoperative CSAs $>40^{\circ}$.

To clarify the available evidence, the purpose of this systematic review and meta-analysis was to determine if acromioplasty reliably decreases the CSA and determine any association with postoperative complications.

\section{Methods}

The PRISMA (Preferred Reporting Items for Systematic Reviews and Meta-Analyses) guidelines were implemented when conducting and reporting this review and meta-analysis [20]. PRISMA checklist were showed in Additional file 1.

\section{Literature search}

We consulted an independent information specialist during the design phase of the search process. A search strategy was developed and performed using PubMed, EMBASE, Web of Science, and Cochrane Library Database up to August 2021 for all English-language publications. The following search terms were used: ("Acromioplasty" OR "Acromion") AND ("Critical shoulder angle" OR "CSA"). We identified potential articles by screening titles and abstracts, and if these meet the inclusion criteria, the full text of the article was obtained. The reference lists from the included articles were analyzed to identify other additional articles.

\section{Inclusion and exclusion criteria}

Studies which met the following inclusion criteria were reviewed for inclusion: (1) clinical trial investigating patients with degenerative RCTs treated by acromioplasty; (2) studies that reported any outcomes, including functional scores, patient-reported outcomes (PROs), and change of CSA; and (3) English-language studies. The exclusion criteria were: (1) animal studies; (2) case reports, review articles, meta-analysis, technical notes, abstract-only articles, and biomechanical studies; (3) studies with missing data on clinical outcomes; and (4) non-English language.

\section{Assessment of study quality}

The Methodological Index for Non-Randomized Studies (MINORS) score was used by two reviewers to evaluate the quality of all included articles [21]. A score of 0 (not reported), 1 (reported but inadequate) or 2 (reported and adequate) was given for each of the 12 items on the MINORS scoring system with a maximum score of 16 for non-comparative studies and 24 for comparative studies. Methodological quality was categorized a priori as follows: a score of $0-8$ or $0-12$ was considered poor, 9-12 or 13-18 was considered intermediate, and 13-16 or 19-24 was considered high for non-comparative and comparative studies, respectively. The level of evidence was reported based on the criteria accepted by the American Academy of Orthopaedic Surgeons [22]. Any 
disagreements between the two reviewers were resolved by consensus after discussion.

\section{Data extraction}

Two reviewers independently selected suitable articles for full-text review by screening all titles and abstracts. Data from the included articles were extracted, including authors, publication date, sample size, level of evidence, patient demographics, study design, and CSA thresholds. If these data were not provided, we contacted the authors directly. Studies were excluded from further analysis when the author could not provide the missing data.

\section{Statistical analysis}

Data from all studies were extracted and tabulated to show the degree of CSA reduction after acromioplasty, repair technique, and CSA thresholds. The primary outcome was the change of CSA after acromioplasty in patients with larger CSAs. A forest plot of the comparative studies was prepared using Review Manager software (RevMan) v.5.4.1, 2020 (The Cochrane Collaboration, Copenhagen, Denmark). The $I^{2}$ statistic was used to assess heterogeneity. An $I^{2} \leq 50 \%$ was considered a slight statistical heterogeneity among studies, and a fixed-effect model was used for analysis. For $I^{2}>50 \%$, the randomeffect model was used for analysis.

\section{Results}

Literature search

A total of 310 unique studies were identified for review. Most of the studies were excluded as they did not meet the inclusion criteria. In total, 75 articles were potentially suitable after the title and abstract screening. From the full-text assessment, 9 articles with 1236 patients met the inclusion criteria. A flowchart of the literature search is provided in Fig. 2.

\section{Patient and study characteristics}

A total of 9 studies involving 1236 patients were included in the meta-analysis with ages ranging from 23 to 82 years. The follow-up period ranged from 12 to 30 months. Of the 9 studies, 8 (88.9\%) were retrospective, $1(11.1 \%)$ was prospective, 5 were comparative, and 4 were case series. Of the included studies, 6 were conducted in Europe (3 in France, 2 in Switzerland, and 1 in Italy), 2 in Asia (1 in China and 1 in Taiwan), and 1 in North America ( 1 in the United States). The publication year of the articles ranged from 2015 to 2021 with 7 studies after 2020. There were 1 Level II, 4 Level III, and 4 Level IV studies. Based on the MINORS criteria (Table 1 ), the mean study quality score was $16.3 \pm 4.5$. For the comparative studies, the mean MINORS score was
$19.4 \pm 1.5$ out of 24 . For the 4 non-comparative studies, the mean MINORS score was $11.3 \pm 0.5$ out of 16 . A total of four high-quality studies, and a further seven intermediate-quality studies were identified. The study characteristics and patient demographics are shown in Table 2.

\section{Surgical procedures}

Eight studies described the technique used for arthroscopic acromioplasty. In total, 1 study described open acromioplasty, 5 lateral acromioplasty, 2 anterior acromioplasty, 1 anterolateral acromioplasty, and 1 lateral and anterolateral acromioplasty (Table 2).

\section{Meta-analysis}

After excluding 4 studies that did not include the mean plus SD of the CSA, a total of 5 studies including 715 patients were used to evaluate acromioplasty outcomes (Table 3$)$. The mean CSA was significantly reduced from $36.1^{\circ} \pm 4.6$ to $33.7^{\circ} \pm 4.2 \quad(p<0.05) \quad$ with a significant decrease in the postoperative compared with the preoperative CSA mean. The mean differences were investigated to determine the overall best estimate of 2.63 (95\% confidence interval (CI) 2.15, 3.11; $I^{2}=0 \%$ ), measured in SD units of the difference in scores $(p<0.00001)$. A forest plot of the paired standardized mean differences is shown in Fig. 3.

\section{Lateral acromioplasty}

Lateral acromioplasty was reported in 5 studies. Gerber et al. [12] reviewed 49 consecutive patients and found that the mean CSA decreased from $37.5^{\circ}$ preoperatively $\left(95 \% \mathrm{CI} 36.7^{\circ}, 38.3^{\circ}\right)$ to $33.9^{\circ}$ postoperatively (95\% CI $\left.33.3^{\circ}, 34.6^{\circ} ; p<0.001\right)$. Franceschetti et al. [23] reported a positive effect in patients with a CSA $>35^{\circ}$ after lateral acromioplasty. A total of 2 studies reported that the mean CSA was reduced by lateral acromioplasty. In addition, Olmos et al. [19] reported that when the preoperative CSA was $>40^{\circ}$, the respective postoperative CSA remained $>35^{\circ}$ in $83.3 \%$ of cases $(p<0.001)$.

\section{Anterior acromioplasty}

There were 2 studies describing anterior acromioplasty to reduce the CSA. Billaud et al. [16] reported that the average CSA for patients preoperatively was $35.9^{\circ}\left( \pm 3.7^{\circ}\right.$; range: $26.2^{\circ}-44.2^{\circ}$ ) and $33^{\circ}$ after the anterior acromioplasty $\left( \pm 3.5^{\circ}\right.$; range: $\left.24.8^{\circ}-41.4^{\circ}\right)$. Girard et al. [24] reported a mean preoperative CSA of $36.1^{\circ}\left( \pm 4.25^{\circ}\right.$; range: $\left.25^{\circ}-48.4^{\circ}\right)$ and a postoperative CSA of $33.5^{\circ}$ $\left( \pm 3.9^{\circ}\right.$; range: $\left.23.8^{\circ}-45.2^{\circ}\right)$, for a significant decrease of $-2.6^{\circ} \pm 2.5^{\circ}(p=0.001)$. 


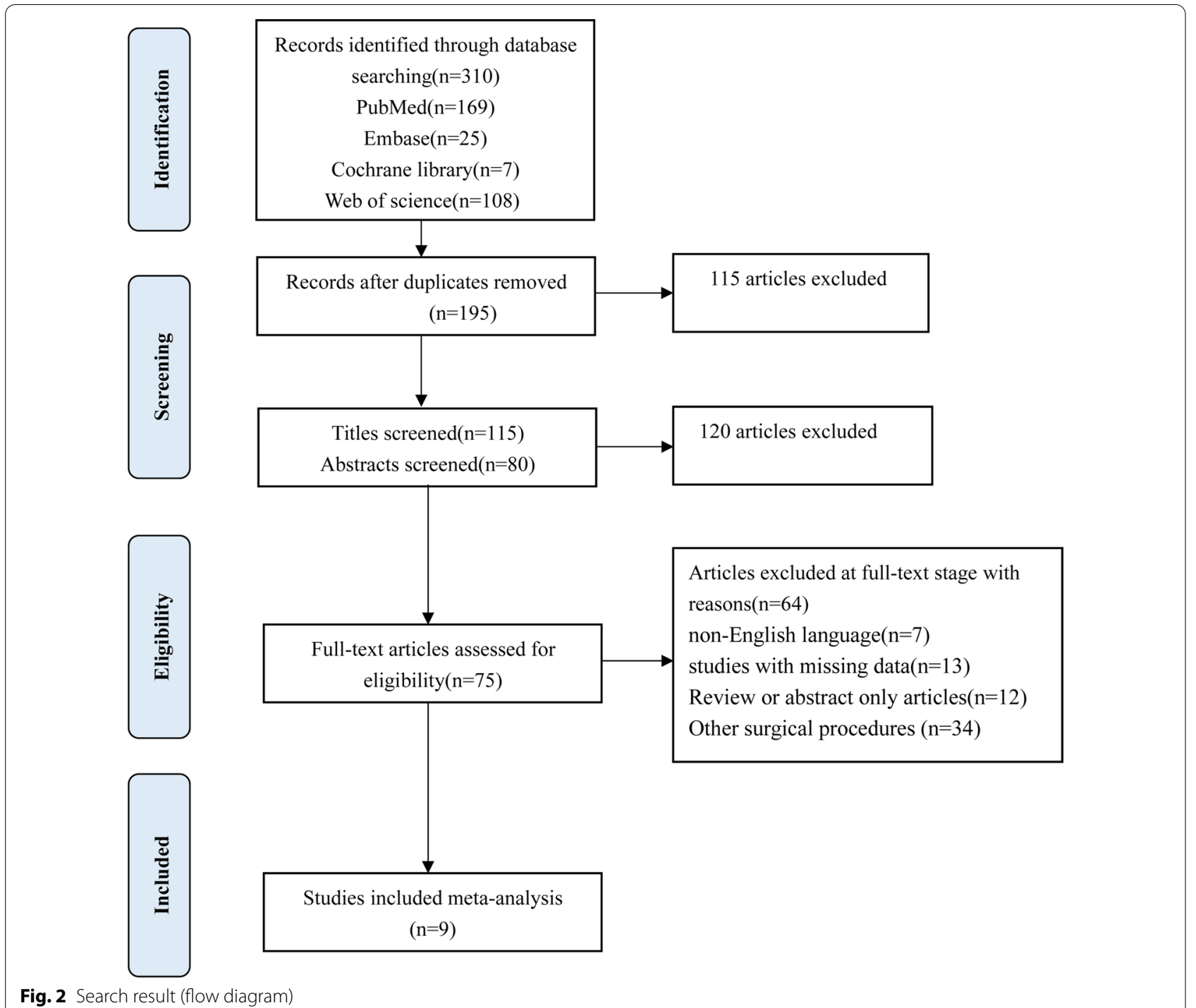

\section{Anterolateral acromioplasty}

Anterolateral acromioplasty was described in 2 studies. Lin et al. [25] reported that 337 participants presented with a mean CSA of $38.4^{\circ} \pm 6.0^{\circ}$ before surgery, which significantly decreased to $35.8^{\circ} \pm 5.9^{\circ}$ after anterolateral acromioplasty $(p<0.05)$. Katthagen et al. [17] reported that anterolateral acromioplasty decreased the CSA by a mean of $1.4^{\circ}\left(95 \% \mathrm{CI} 0.8^{\circ}, 1.9^{\circ}\right)$.

\section{Lateral versus anterolateral acromioplasty}

One study reported that the effect on the CSA of lateral acromioplasty was more significant compared to anterolateral acromioplasty. Long et al. [26] found that the reduction in CSA was $2.6^{\circ} \pm 1.8^{\circ}$ by anterolateral acromioplasty and $4.4^{\circ} \pm 1.5^{\circ}$ by lateral acromioplasty. In addition, an anatomic cadaveric study reported that the mean preintervention CSA $\left(34.3^{\circ} \pm 2.1^{\circ}\right)$ decreased via anterolateral acromioplasty $\left(33.1^{\circ} \pm 2.0^{\circ}, p<0.001\right)$ and further decreased by lateral acromioplasty $\left(31.5^{\circ} \pm 1.7^{\circ}, p<0.001\right)$ [17]. An anatomical study [18] reported that lateral acromioplasty of $5 \mathrm{~mm} / 10 \mathrm{~mm}$ reduced the CSA significantly more than anterolateral acromioplasty of $5 \mathrm{~mm} / 10 \mathrm{~mm}$ [5 mm: $2.3^{\circ} \pm 0.8^{\circ}$ vs. $\left.1.2^{\circ} \pm 1.1^{\circ}, p=0.0002\right] /[10 \mathrm{~mm}$ : $4.8^{\circ} \pm 1.3^{\circ}$ vs. $\left.2.7^{\circ} \pm 1.7^{\circ}, p=0.0001\right]$.

\section{Functional outcomes and complications}

The most universally used functional outcome measure was the Constant-Murley scores reported in 3 studies. One study reported that the scores had improved from 59 points (range, 54-64 points) preoperatively to 74 points (range, $70-78$ points) postoperatively at a mean 


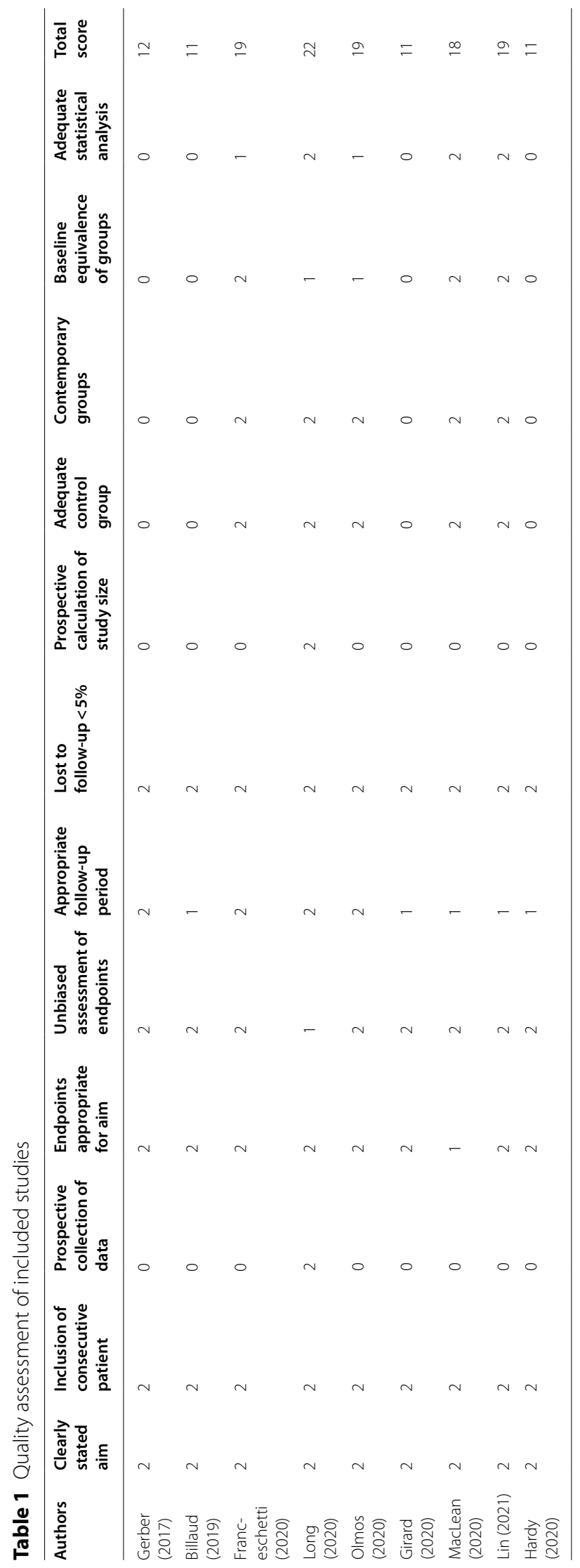


Table 2 Characteristics of included studies

\begin{tabular}{|c|c|c|c|c|c|c|c|c|c|}
\hline $\begin{array}{l}\text { Lead author } \\
\text { (year) }\end{array}$ & Location & $\begin{array}{l}\text { Total } \\
\text { participant }\end{array}$ & Age (years) & $\begin{array}{l}\text { Gender } \\
\text { (male\%) }\end{array}$ & $\begin{array}{l}\text { Follow-up } \\
\text { (months) }\end{array}$ & $\begin{array}{l}\text { Study } \\
\text { design (level } \\
\text { of evidence) }\end{array}$ & $\begin{array}{l}\text { Measurement } \\
\text { method of } \\
\text { CSA }\end{array}$ & $\begin{array}{l}\text { Repair } \\
\text { Technique }\end{array}$ & CSA threshold \\
\hline Gerber (2017) & Switzerland & 49 & $39-76$ & $83.70 \%$ & 30 & $\begin{array}{l}\text { Case } \\
\text { Series(IV) }\end{array}$ & MRI & $\begin{array}{l}\text { Arthroscopic } \\
\text { lateral AP }\end{array}$ & NR \\
\hline Billaud (2019) & France & 90 & $41-76$ & $61.10 \%$ & $N R$ & $\begin{array}{l}\text { Case } \\
\text { Series(IV) }\end{array}$ & Radiographs & $\begin{array}{l}\text { Arthroscopic } \\
\text { anterior AP }\end{array}$ & NR \\
\hline $\begin{array}{l}\text { Franceschetti } \\
\text { (2020) }\end{array}$ & Italy & 289 & 57 & $46.70 \%$ & 28 & $\begin{array}{l}\text { Retrospective } \\
\text { comparative } \\
\text { study(III) }\end{array}$ & Radiographs & $\begin{array}{l}\text { Arthroscopic } \\
\text { lateral AP }\end{array}$ & 35 \\
\hline Long (2020) & China & 60 & $N R$ & NR & 12 & $\begin{array}{l}\text { Prospective } \\
\text { comparative } \\
\text { study(II) }\end{array}$ & 3D-CT & $\begin{array}{l}\text { Arthroscopic } \\
\text { lateral and } \\
\text { anterolateral } \\
\text { AP }\end{array}$ & 33 \\
\hline Olmos (2020) & France & 90 & 58 & $60 \%$ & 12 & $\begin{array}{l}\text { Retrospective } \\
\text { comparative } \\
\text { study(III) }\end{array}$ & Radiographs & $\begin{array}{l}\text { Arthroscopic } \\
\text { lateral AP }\end{array}$ & 35 \\
\hline Girard (2020) & France & 148 & $29-80$ & $57.40 \%$ & NR & $\begin{array}{l}\text { Case } \\
\text { Series(IV) }\end{array}$ & Radiographs & $\begin{array}{l}\text { Open ante- } \\
\text { rior AP }\end{array}$ & 35 \\
\hline $\begin{array}{l}\text { MacLean } \\
(2020)\end{array}$ & USA & 71 & 58 & $64.80 \%$ & NR & $\begin{array}{l}\text { Retrospective } \\
\text { comparative } \\
\text { study(III) }\end{array}$ & Radiographs & $\begin{array}{l}\text { Arthroscopic } \\
\text { lateral AP }\end{array}$ & 35 \\
\hline $\operatorname{Lin}(2021)$ & Taiwan & 337 & 64.2 & $47.50 \%$ & NR & $\begin{array}{l}\text { Retrospective } \\
\text { comparative } \\
\text { study(III) }\end{array}$ & Radiographs & $\begin{array}{l}\text { Arthroscopic } \\
\text { anterolateral } \\
\text { AP }\end{array}$ & 38 \\
\hline Hardy (2020) & France & 102 & $23-82$ & $37.20 \%$ & NR & $\begin{array}{l}\text { Case } \\
\text { Series(IV) }\end{array}$ & Radiographs & $\begin{array}{l}\text { Arthroscopic } \\
\text { lateral AP }\end{array}$ & 35 \\
\hline
\end{tabular}

NR, not reported; CSA, critical shoulder angle; AP, acromioplasty; MRI, magnetic resonance imaging; 3D-CT, three-dimensional computerized tomography

Table 3 The reduction in CSA after acromioplasty

\begin{tabular}{lllllll}
\hline Study & \multicolumn{2}{l}{ Preoperative } & & & \multicolumn{2}{l}{ Postoperative } \\
\cline { 2 - 3 } & Mean & SD & Total & & Mean & SD \\
\hline Billaud (2019) & 35.9 & 3.7 & 90 & 33 & 3.5 & Total \\
Girard (2020) & 36.1 & 4.25 & 148 & 33.5 & 30 \\
MacLean (2020) & 35.5 & 4.4 & 4.4 & 102 & 34.5 & 3.9 \\
Hardy (2021) & 34.7 & 6 & 337 & 31.7 & 3.8 & 148 \\
Lin (2021) & 38.4 & & & 35.8 & 3.7 & 102 \\
\hline
\end{tabular}

CSA, critical shoulder angle; SD, standard deviation

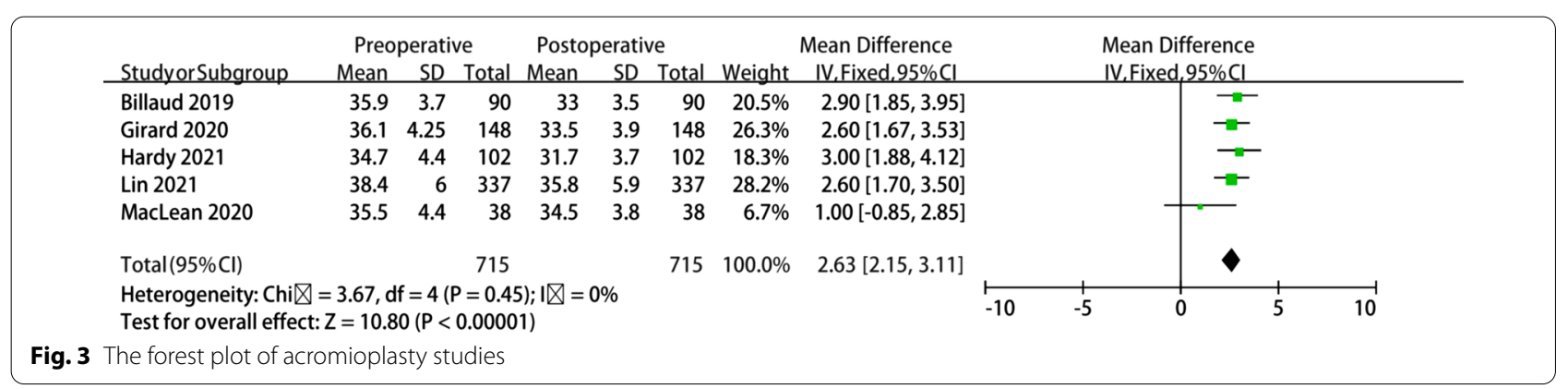


follow-up of 30 months (range, 12-47 months) [12]. Another study also found a significant improvement in Constant-Murley score after lateral acromioplasty [23]. No complications were reported in any of the included studies related to acromioplasty.

\section{Discussion}

This systematic review and meta-analysis aimed to determine if acromioplasty reliably decreases the CSA and to describe any association with postoperative complications. Our main findings indicate that the acromioplasty procedure can effectively reduce the CSA, the effect of lateral acromioplasty on the CSA is more significant compared to anterolateral acromioplasty, and acromioplasty is not associated with complications based on short-term follow-up.

The CSA, originally introduced by Moor et al. [10], is thought to influence the risk of degenerative RCTs, with a range of $30^{\circ}$ to $35^{\circ}$ generally considered to be a "favorable range." Studies have found that individuals with degenerative RCTs have significantly larger CSAs $\left(\geq 35^{\circ}\right)$ compared to those with asymptomatic shoulders and that a $\mathrm{CSA}<30^{\circ}$ is associated with glenohumeral osteoarthritis. Gerber et al. [27, 28] confirmed that a large CSA alters glenohumeral biomechanics such that could induce supraspinatus overload and that a low CSA increased the load of the humeral head on the glenoid. Furthermore, Garcia et al. [11] reported that contrary to previous studies, the average CSA values correlated with RCTs, where CSAs $>38^{\circ}$ (range: $35^{\circ}-39^{\circ}$ ) seemed to be a consistent predictor of RCTs and indicated an increased risk of retear after surgical repair. However, a meta-analysis showed that while the CSA can be reliably measured, the difference in the CSA between cases and controls varied from very large to almost no difference, and it is difficult to understand the strength and association between the CSA and RCT with the current evidence [13]. In addition, Cerciello et al. [29] confirmed no significant differences in CSA values between patients who had undergone shoulder replacement and experienced late cuff failure and those in whom the same procedure had been successful. Therefore, larger populations are needed to confirm this trend.

CSAs in partial-thickness tears and full-thickness tears were reported in some studies. Pandey et al. [30] reported that higher CSAs are associated with a fullthickness tear but not with partial tears. A meta-regression analysis revealed that the sensitivity of CSA could be higher for differentiating full-thickness RCTs and normal patients [9]. However, another study reported that the mean CSA in patients with full-thickness tears was $34.3 \pm 4.2^{\circ}$ and those with partial-thickness tears was $32.6 \pm 3.2^{\circ}(p=0.08)$ [31]. Furthermore, Chalmers et al. [32] demonstrated that CSA is not correlated with tear size or progression and does not seem to change with time. Therefore, further studies are needed to clarify whether larger CSA is only associated with full-thickness tears.

The methods used to measure CSA mainly include radiographs, $\mathrm{CT}$ imaging, and magnetic resonance imaging (MRI). Spiegl et al. [33] reported that interobserver and intra-observer agreement on radiographs were 0.87 (95\% CI 0.78, 0.93) and 0.91 (95\% CI 0.82, 0.96), respectively. Therefore, they considered that CSA measurements obtained on radiographs demonstrated excellent interobserver agreement with less variability than CSA measurements by MRI, especially in osteoarthritis patients. Furthermore, Samy et al. [34] measured the CSA of 60 shoulders by radiographs and multiplanar reconstructions of corresponding $\mathrm{CT}$ scans and found that the measurements of the CSA on anterior-posterior radiographs and CT scans are highly correlated with negligible inter-modality differences. In the present analysis, radiographs were used in 7 studies, CT in 1 study, and MRI in 1 study.

There is no standard evaluation of acromial resection. Gerber et al. [12] reported that the mediolateral diameter of the acromion was reduced by an average of $6 \mathrm{~mm}$ (range, 3-8 $\mathrm{mm}$ ) after lateral acromioplasty. In another anatomic cadaveric study, researchers demonstrated that a $5 \mathrm{~mm}$ lateral acromion resection reduced the CSA significantly and did not damage the deltoid origin [17]. In addition, Kaiser et al. [18] reported that lateral acromioplasty of $5 / 10 \mathrm{~mm}$ reduced the CSA significantly $(5 \mathrm{~mm}$ : $2.3^{\circ} \pm 0.8^{\circ}$ [range: $0.7^{\circ}-3.6^{\circ}$ ] vs. $10 \mathrm{~mm}: 4.8^{\circ} \pm 1.3^{\circ}$ [range: $\left.2.1^{\circ}-7^{\circ}\right]$ ). Although lateral acromioplasty up to $10 \mathrm{~mm}$ has been considered a safe technique [12, 17], other studies found that over-resection of the acromion has potential complications, including acromial fractures and detachment of the deltoid origin $[35,36]$.

Currently, altering the CSA by arthroscopic acromioplasty is a common strategy. Girard et al. [24] compared the effect between arthroscopy and open surgery and found that surgical technique did not affect change in CSA (open surgery: $-2.3^{\circ} \pm 1.9^{\circ}$ [range: $-6.3^{\circ}$ to $-1^{\circ}$ ] vs. arthroscopy: $-2.7^{\circ} \pm 2.7^{\circ} \quad$ [range: $-10.5^{\circ}$ to $-5^{\circ}$ ]; $p=0.06$ ). In the present systematic review, 8 studies described the techniques used for arthroscopic acromioplasty, and one studies described open acromioplasty. Therefore, arthroscopic acromioplasty was a useful and safe procedure.

There remains controversy regarding the usefulness of acromioplasty performed at the time of rotator cuff repair (RCR). Some studies have reported no difference in functional outcome scores for patients who underwent arthroscopic RCR with or without acromioplasty 
[37-39]. In addition, several studies concluded that the reduction in the CSA does not improve functional results postoperatively [40, 41]. However, some studies reported that a large CSA increased the risk of retearing after RCR [11, 42, 43]. Therefore, future studies are warranted to clarify the usefulness of acromioplasty at the time of RCR.

\section{Study strengths and limitations}

This study has several strengths. First, it is the first systematic review to determine whether acromioplasty reliably decreases the CSA and if it is associated with complications. Second, we included all studies associated with acromioplasty aimed to reduce the CSA. Finally, we assessed the studies according to the PRISMA statement to improve rigor.

This systematic review also has some limitations. First, this systematic review included 9 studies, of which, 8 (88.9\%) were retrospective and only 1 study (11.1\%) was prospective. The retrospective studies were limited by imperfect information and loss to follow-up in medical records. The results of this systematic review may be affected by the inclusion of lower-quality studies. Second, only six studies provided indications for acromioplasty, and the type of RCTs was not specified; therefore, we could not analyze the effect of acromioplasty for different types of RCTs, and future studies should evaluate the postoperative outcomes of different rotator cuff types. In addition, due to the variety of surgical procedures, the evaluation results may not be reliable. Finally, there are only 2 studies with a followup time of more than 2 years and others that did not provide a follow-up which may affect the results of this study. Because the data regarding functional outcomes and complications could not be uniformly compared, a long-term outcome analysis of acromioplasty was not feasible.

\section{Conclusions}

The present systematic review and meta-analysis found that acromioplasty significantly reduced CSA overall, notably in patients with a high preoperative CSA. In addition, the effect on the CSA after lateral acromioplasty is more significant compared to anterolateral acromioplasty. Acromioplasty was not associated with complications during short-term follow-up. Finally, there is a strong need for future studies to clarify the usefulness for acromioplasty at the time of RCR.
Abbreviations

CSA: Critical shoulder angle; RCTs: Rotator cuff tears; PROs: Patient-reported outcomes; MINORS: The methodological index for non-randomized studies; $\mathrm{Cl}$ : Confidence interval.

\section{Supplementary Information}

The online version contains supplementary material available at https://doi. org/10.1186/s13018-022-02927-7.

Additional file 1. PRISMA checklist of the meta-analysis.

\section{Acknowledgements}

The authors thank the financial support of the Second Hospital of Lanzhou University, "Cuiying Technology Innovation" program, clinical top-notch technology research project, clinical study of autologous osteochondral transplantation for the treatment of recurrent shoulder dislocation in young adults, and the Gansu Provincial Department of Science and Technology, Natural Science Foundation Project, Study on the mechanism of autologous osteochondral transplantation in the treatment of recurrent shoulder dislocation.

\section{Authors' contributions}

$M Z$ collected the literature and wrote the article. $X Y$ and $J J$ revised the article. $Z Y$ and BZ designed the study. TL prepared figures and tables. All authors contributed toward data analysis, drafting and critically revising the paper and agree to be accountable for all aspects of the work. All authors read and approved the final manuscript.

\section{Funding}

This work was supported by The Second Hospital of Lanzhou University, "Cuiying Technology Innovation" program, clinical top-notch technology research project, CY2019-BJ04, clinical study of autologous osteochondral transplantation for the treatment of recurrent shoulder dislocation in young adults, and the Gansu Provincial Department of Science and Technology, Natural Science Foundation Project, 20JR10RA723, Study on the mechanism of autologous osteochondral transplantation in the treatment of recurrent shoulder dislocation.

\section{Availability of data and materials}

The datasets generated during and/or analyzed during the current study are available from the corresponding author on reasonable request.

\section{Declarations}

Ethics approval and consent to participate

Not application.

\section{Consent for publication}

Informed consent was obtained from all individual participants included in the study. Patients signed informed consent regarding publishing their data and photographs.

\section{Competing interests}

The authors, their immediate families, and any research foundations with which they are affiliated have not received any financial payments or other benefits from any commercial entity related to the subject of this article. Institutional review board approval was not required for this study.

Received: 20 October 2021 Accepted: 6 January 2022

Published online: 15 January 2022

References

1. Clayton RA, Court-Brown CM. The epidemiology of musculoskeletal tendinous and ligamentous injuries. Injury. 2008;39(12):1338-44. https:// doi.org/10.1016/j.injury.2008.06.021. 
2. Jain NB, Higgins LD, Losina E, Collins J, Blazar PE, Katz JN. Epidemiology of musculoskeletal upper extremity ambulatory surgery in the United States. BMC Musculoskelet Disord. 2014;15:4. https://doi.org/10.1186/ 1471-2474-15-4.

3. Reilly P, Macleod I, Macfarlane R, Windley J, Emery RJ. Dead men and radiologists don't lie: a review of cadaveric and radiological studies of rotator cuff tear prevalence. Ann R Coll Surg Engl. 2006;88(2):116-21. https://doi. org/10.1308/003588406X94968.

4. Tashjian RZ. Epidemiology, natural history, and indications for treatment of rotator cuff tears. Clin Sports Med. 2012;31(4):589-604. https://doi.org/ 10.1016/j.csm.2012.07.001.

5. Andrade R, Correia AL, Nunes J, Xara-Leite F, Calvo E, Espregueira-Mendes J, Sevivas N. Is bony morphology and morphometry associated with degenerative full-thickness rotator cuff tears? A systematic review and meta-analysis. Arthrosc. 2019;35(12):3304-15 e2. https://doi.org/10.1016/j. arthro.2019.07.005.

6. Nyffeler RW, Werner CM, Sukthankar A, Schmid MR, Gerber C. Association of a large lateral extension of the acromion with rotator cuff tears. J Bone Joint Surg Am. 2006;88(4):800-5. https://doi.org/10.2106/JBJS.D.03042.

7. Musil D, Sadovsky P, Rost M, Stehlik J, Filip L. Relationship of acromial morphology and rotator cuff tears. Acta Chir Orthop Traumatol Cech. 2012;79(3):238-42. https://doi.org/10.2106/JBJS.D.03042.

8. Lin CL, Chen YW, Lin LF, Chen CP, Liou TH, Huang SW. Accuracy of the critical shoulder angle for predicting rotator cuff tears in patients with nontraumatic shoulder pain. Orthop J Sports Med. 2020;8(5):2325967120918995. https://doi.org/10.1177/2325967120 918995.

9. Song JG, Yun SJ, Song YW, Lee SH. High performance of critical shoulder angle for diagnosing rotator cuff tears on radiographs. Knee Surg Sports Traumatol Arthrosc. 2019;27(1):289-98. https://doi.org/10.1007/ s00167-018-5247-1.

10. Moor BK, Bouaicha S, Rothenfluh DA, Sukthankar A, Gerber C. Is there an association between the individual anatomy of the scapula and the development of rotator cuff tears or osteoarthritis of the glenohumeral joint?: A radiological study of the critical shoulder angle. Bone Joint J. 2013;95-B(7):935-41. https://doi.org/10.1302/0301-620X.95B7.31028.

11. Garcia GH, Liu JN, Degen RM, Johnson CC, Wong AC, Dines DM, Gulotta LV, Dines JS. Higher critical shoulder angle increases the risk of retear after rotator cuff repair. J Shoulder Elbow Surg. 2017;26(2):241-5. https://doi. org/10.1016/j.jse.2016.07.009.

12. Gerber C, Catanzaro S, Betz M, Ernstbrunner L. Arthroscopic correction of the critical shoulder angle through lateral acromioplasty: a safe adjunct to rotator cuff repair. Arthroscopy. 2018;34(3):771-80. https://doi.org/10. 1016/j.arthro.2017.08.255.

13. Rojas Lievano J, Bautista M, Woodcock S, Fierro G, Gonzalez JC. Controversy on the association of the critical shoulder angle and the development of degenerative rotator cuff tears: is there a true association? A meta-analytical approach. Am J Sports Med. 2021. https://doi.org/10. 1177/03635465211027305.

14. Neer CS 2nd. Anterior acromioplasty for the chronic impingement syndrome in the shoulder: a preliminary report. J Bone Joint Surg Am. 1972;54(1):41-50.

15. Ellman H. Arthroscopic subacromial decompression: analysis of one- to three-year results. Arthroscopy. 1987;3(3):173-81. https://doi.org/10. 1016/S0749-8063(87)80061-0.

16. Billaud A, Cruz-Ferreira E, Pesquer L, Abadie P, Carlier Y, Flurin PH. Does the critical shoulder angle decrease after anterior acromioplasty? Arch Orthop Trauma Surg. 2019;139(8):1125-32. https://doi.org/10.1007/ s00402-019-03163-1.

17. Katthagen JC, Marchetti DC, Tahal DS, Turnbull TL, Millett PJ. The effects of arthroscopic lateral acromioplasty on the critical shoulder angle and the anterolateral deltoid origin: an anatomic cadaveric study. Arthroscopy. 2016;32(4):569-75. https://doi.org/10.1016/j.arthro.2015.12.019.

18. Kaiser D, Bachmann E, Gerber C, Meyer DC. Influence of the site of acromioplasty on reduction of the critical shoulder angle (CSA) —an anatomical study. BMC Musculoskelet Disord. 2018;19(1):371. https://doi. org/10.1186/s12891-018-2294-1.

19. Olmos MI, Boutsiadis A, Swan J, Brossard P, Barthelemy R, Delsol P, Barth J. Lateral acromioplasty cannot sufficiently reduce the critical shoulder angle if preoperatively measured over 40 degrees. Knee Surg
Sports Traumatol Arthrosc. 2021;29(1):240-9. https://doi.org/10.1007/ s00167-020-05951-4.

20. Moher D, Liberati A, Tetzlaff J, Altman DG, Group P. Preferred reporting items for systematic reviews and meta-analyses: the PRISMA Statement. Open Med. 2009;3(3):e123-30.

21. Slim K, Nini E, Forestier D, Kwiatkowski F, Panis Y, Chipponi J. Methodological index for non-randomized studies (minors): development and validation of a new instrument. ANZ J Surg. 2003;73(9):712-6. https://doi. org/10.1046/j.1445-2197.2003.02748.x.

22. Schmidt AH, Zhao G, Turkelson C. Levels of evidence at the AAOS meeting: can authors rate their own submissions, and do other raters agree? J Bone Joint Surg Am. 2009;91(4):867-73. https://doi.org/10.2106/JBJS.G. 01233.

23. Franceschetti E, Giovannetti de Sanctis E, Palumbo A, Ranieri R, Casti P, Mencattini A, Maffulli N, Franceschi F. Lateral acromioplasty has a positive impact on rotator cuff repair in patients with a critical shoulder angle greater than 35 degrees. J Clin Med. 2020. https://doi.org/10.3390/jcm91 23950.

24. Girard M, Colombi R, Azoulay V, Laumonerie P, Martel M, Mansat P, Bonnevialle N. Does anterior acromioplasty reduce critical shoulder angle? Orthop Traumatol Surg Res. 2020;106(6):1101-6. https://doi.org/10.1016/j. otsr.2020.04.013.

25. Lin CL, Lin LF, Hsu TH, Lin LC, Lin CH, Huang SW. Acromioplasty reduces critical shoulder angle in patients with rotator cuff tear. PLOS ONE. 2021;16(6):e0253282. https://doi.org/10.1371/journal.pone.0253282.

26. Long Y, Hou J, Tang Y, Li F, Yu M, Zhang C, Yang R. Effect of arthroscopic acromioplasty on reducing critical shoulder angle: a protocol for a prospective randomized clinical trial. BMC Musculoskelet Disord. 2020;21(1):819. https://doi.org/10.1186/s12891-020-03818-w.

27. Gerber C, Snedeker JG, Baumgartner D, Viehofer AF. Supraspinatus tendon load during abduction is dependent on the size of the critical shoulder angle: a biomechanical analysis. J Orthop Res. 2014;32(7):952-7. https://doi.org/10.1002/jor.22621.

28. Viehofer AF, Gerber C, Favre P, Bachmann E, Snedeker JG. A larger critical shoulder angle requires more rotator cuff activity to preserve joint stability. J Orthop Res. 2016;34(6):961-8. https://doi.org/10.1002/jor.23104.

29. Cerciello S, Monk AP, Visona E, Carbone S, Edwards TB, Maffulli N, Walch $G$. The influence of critical shoulder angle on secondary rotator cuff insufficiency following shoulder arthroplasty. Arch Orthop Trauma Surg. 2017;137(7):913-8. https://doi.org/10.1007/s00402-017-2707-x.

30. Pandey V, Vijayan D, Tapashetti S, Agarwal L, Kamath A, Acharya K, Maddukuri S, Willems WJ. Does scapular morphology affect the integrity of the rotator cuff? J Shoulder Elbow Surg. 2016;25(3):413-21. https://doi. org/10.1016/j.jse.2015.09.016.

31. Shinagawa K, Hatta T, Yamamoto N, Kawakami J, Shiota Y, Mineta M, Itoi E. Critical shoulder angle in an East Asian population: correlation to the incidence of rotator cuff tear and glenohumeral osteoarthritis. J Shoulder Elbow Surg. 2018;27(9):1602-6. https://doi.org/10.1016/j.jse.2018.03.013.

32. Chalmers PN, Salazar D, Steger-May K, Chamberlain AM, Yamaguchi K, Keener JD. Does the critical shoulder angle correlate with rotator cuff tear progression? Clin Orthop Relat Res. 2017;475(6):1608-17. https://doi.org/ 10.1007/s11999-017-5249-1.

33. Spiegl UJ, Horan MP, Smith SW, Ho CP, Millett PJ. The critical shoulder angle is associated with rotator cuff tears and shoulder osteoarthritis and is better assessed with radiographs over MRI. Knee Surg Sports Traumatol Arthrosc. 2016;24(7):2244-51. https://doi.org/10.1007/ s00167-015-3587-7.

34. Bouaicha S, Ehrmann C, Slankamenac K, Regan WD, Moor BK. Comparison of the critical shoulder angle in radiographs and computed tomography. Skeletal Radiol. 2014;43(8):1053-6. https://doi.org/10.1007/ s00256-014-1888-4.

35. Green A, Griggs S, Labrador D. Anterior acromial anatomy: relevance to arthroscopic acromioplasty. Arthroscopy. 2004;20(10):1050-4. https://doi org/10.1016/j.arthro.2004.08.014.

36. Matthews LS, Burkhead WZ, Gordon S, Racanelli J, Ruland L. Acromial fracture: a complication of arthroscopic subacromial decompression. J Shoulder Elbow Surg. 1994;3(4):256-61. https://doi.org/10.1016/S10582746(09)80044-X.

37. Abrams GD, Gupta AK, Hussey KE, Tetteh ES, Karas V, Bach BR Jr, Cole BJ, Romeo AA, Verma NN. Arthroscopic repair of full-thickness rotator cuff tears with and without acromioplasty: randomized prospective trial with 
2-year follow-up. Am J Sports Med. 2014;42(6):1296-303. https://doi.org/ 10.1177/0363546514529091.

38. Buss DD, Stern SH, Tervola N, McCarty LP 3rd, Giveans MR. Prevalence of rotator cuff repairs with and without concomitant subacromial decompressions has not changed. HSS J. 2018;14(2):123-7. https://doi.org/10. 1007/s11420-017-9594-0.

39. MacDonald P, McRae S, Leiter J, Mascarenhas R, Lapner P. Arthroscopic rotator cuff repair with and without acromioplasty in the treatment of full-thickness rotator cuff tears: a multicenter, randomized controlled trial. J Bone Joint Surg Am. 2011;93(21):1953-60. https://doi.org/10.2106/ JBJS.K.00488.

40. Kirsch JM, Nathani A, Robbins CB, Gagnier JJ, Bedi A, Miller BS. Is there an association between the "critical shoulder angle" and clinical outcome after rotator cuff repair? Orthop J Sports Med. 2017;5(4):2325967117702126. https://doi.org/10.1177/2325967117 702126.

41. Lee M, Chen JY, Liow MHL, Chong HC, Chang P, Lie D. Critical shoulder angle and acromial index do not influence 24-month functional outcome after arthroscopic rotator cuff repair. Am J Sports Med. 2017;45(13):298994. https://doi.org/10.1177/0363546517717947.

42. Li H, Chen Y, Chen J, Hua Y, Chen S. Large critical shoulder angle has higher risk of tendon retear after arthroscopic rotator cuff repair. Am J Sports Med. 2018;46(8):1892-900. https://doi.org/10.1177/0363546518 767634.

43. Scheiderer B, Imhoff FB, Johnson JD, Aglio J, Cote MP, Beitzel K, Imhoff AB, Arciero RA, Mazzocca AD, Morikawa D. Higher critical shoulder angle and acromion index are associated with increased retear risk after isolated supraspinatus tendon repair at short-term follow up. Arthroscopy. 2018;34(10):2748-54. https://doi.org/10.1016/j.arthro.2018.05.029.

\section{Publisher's Note}

Springer Nature remains neutral with regard to jurisdictional claims in published maps and institutional affiliations.

- fast, convenient online submission

- thorough peer review by experienced researchers in your field

- rapid publication on acceptance

- support for research data, including large and complex data types

- gold Open Access which fosters wider collaboration and increased citations

- maximum visibility for your research: over 100M website views per year

At BMC, research is always in progress.

Learn more biomedcentral.com/submissions 